\title{
Is There an EKC Relevant to the Industrial Emission of Water Pollution for SEMC and EU Countries?
}

\author{
Imen Trabelsi \\ Department of economics university of SFAX-TUNISIA \\ CODECI Research Unit, Faculty of Economics and Management \\ Road of aeroport km 4.5 b.p 3018, Sfax, Tunisia \\ E-mail: trabelsiimen@planet.tn
}

Received: March 21, 2012 Accepted: April 5, 2012 Online Published: April 27, 2012

doi:10.5296/emsd.v1i1.1535 URL: http://dx.doi.org/10.5296/emsd.v1i1.1535

\begin{abstract}
The Environmental Kuznet's curve hypothesis admits the existence of an inverted U-shaped relationship between economic growth, generally approximated by GDP per capita, and environmental degradation. Despite the abundance of empirical literature on the environmental Kuznets curve, so far no study has been dealt with the relationship between economic growth and environmental pollution to Southern Eastern Mediterranean Counties SEMC and the European Union areas. Hence, we have therefore tried to extract an EKC specific for these two regions by focusing on the water pollution as an indicator of environmental degradation. For this aim, we have applied the technique of cointegration panel data for both samples in question over the period ranging from 1980 to 2005 . Throughout this work, we have detected the existence of an environmental Kuznets curve with an inverted U-shaped specific to each sample. These curves admit two different turning points reflecting the differences between their levels of development.
\end{abstract}

Keywords: Environmental Kuznets Curve, Water Pollution, Economic Growth, Cointegration, Panel

Jel classification: Q56, Q53, C33 


\section{Introduction}

For some proponents authors of "limits to growth" theory, an economic activity growth requires a high consumption of energy and inputs, and engenders more and more wastes. In fact, these wastes mine the "absorptive capacity" of the biosphere, adverse consequences on the environmental quality and reduce the general well-being of humankind. Actually, the degradation of basic resources in turn, is likely to engender the economy itself by undermining the potential for future economic growth. For these authors, the only way to restore the environment and economic activity is to stop economic growth and to make transition to a steady state of the economy.

In contrast with this very pessimistic assumption, the Environmental Kuznets Curve (EKC) assumes the existence of a certain relationship in the form of an inverted $U$ between a variety of indicators of environmental degradation and income per capita. In other words, while environmental degradation is initially emphasized or rather accentuated through economic growth, it is soon afterwards, likely to be decoupled from it and it would start to decrease after reaching a critical level of income per capita.

It is worth noting that, the Environmental Kuznets Curve (EKC) has its origins in the Kuznets curve (1955), which initially assumed the existence of a positive relationship between inequality in income distribution and income growth in the form of an inverted-U curve. Since the early's 90s, this inverted U curve has become the focus and the subject matter of many recurrent studies. These latter's were carried out by Grossman and Krueger (1991) on potential environmental impacts of North American Free Trade Area NAFTA, then by Shafik and Bandyopadhyay (1992) as the report center on World Development, and that of Panayotou $(1993,2003)$ relevant to 'International Labor Organization". The reached findings indicate the existence through cross-sectional analysis, of a certain correlation in the form of an inverted $U$ flanked by some pollution indicators and income per capita. Panayotou (1993) is the pioneer who initiated a label to this U shaped link by dubbing it as the "Environmental Kuznets Curve", due to its resemblance to the inverted-U relationship existing between income inequality and economic development.

This hypothesis, instead of describing economic growth as being a threat to the environment and recommending the growth cessation, shows a certain harmony among environmental protection and potential economic growth. It provides to the developing countries, the possibility of achieving economic development, as that achieved by their predecessors, the developed countries.

In the remainder of this work, a review of the literature will be displayed in the first place. In the second one, we will be discussing our empirical model. Finally, we will move to the analysis and results interpretation obtained throughout the estimation stage. 


\section{Literature Review}

Ever since statistics on the quality of the environment were available, the EKC hypothesis under reduced form of correlation between income level and various environmental indicators has been easily tested econometrically. In fact, starting from the earl's 90s, compilation and data publication relevant to pollution concentration and emission by the Global Environment Monitoring System (GEMS), the World Bank Indicator (WDI), the World Resource Institute (WRI), the Organisation for Economic Co-operation and Development (OECD) and the United Nation environmental databases, have triggered an unprecedented inspiration to research on EKC. Given that the appearance of Grossman and Krueger (1991) first paper on this subject, over a hundred papers have been interested in this theme, most of which have confirmed the existence of such a curve.

In fact, these papers results confirm the fact that the EKC hypothesis seems to be tested and satisfactory for only some environmental indicators but not all of them. Indeed, this hypothesis is verified essentially as far as air pollution indicators are concerned possibly with the exception of $\mathrm{CO}_{2}$ emissions (Panayoto, 1997; Cavlovic and al. 2000; Azomahou and al. 2006; Elif and al, 2009; Abdul Jalil and Syedf Mahmudb, 2009). Several studies have exposed that $\mathrm{CO}_{2}$ emissions are less likely to conform the EKC hypothesis. The analysis of Moonrow and Unruh (1997) illustrate that the correlation between $\mathrm{CO}_{2}$ emissions and GDP per capita is affected by countries economic conditions. They indicate that among 60 OECD countries subject of their study, only three countries EKC have shown an EKC with a form of N. This curve is evidently highlighted for the case of $\mathrm{CO}_{2}$ (Dinda and al 2004, Stern and Common, 2001; Cole 2004; Elif and al 2009) and to a lesser extent in the case of solid particles (El-Fadel and Massoud 2000, Quah and Boon, 2003).

However, we can observe the unstable EKC examining studies involving different samples of countries in their database. A striking example of this appears clearly when we compare the study of Stern and Common (2001) to that of Selden and Song (1994). Including only 22 OECD countries in their estimation, Selden and Song (1994) discovered an EKC with a turning point of around $8000 \$$ to $10000 \$$. By expanding the database to 73 countries, with a great deal of new data from the developing world, Stern and Common (2001) have revealed that the "turning point of EKC" becomes much higher when the developing countries data are included or estimated separately. If their sub-sample comprising the OECD countries reproduces a turning point (9181\$), quite similar to that of Selden and Song (1994), the overall sample as well as that of the countries outside the OECD indicates turning points that are much higher: $54.199 \$$ for the overall sample and $343.689 \$$ for countries outside the OECD. Other paired comparisons also confirm the sensitivity of the EKC shape to the choice of country samples. Thus, Vincent (1997) argues that the emission of suspended particulate matter (SPM) increase with the rate of income level for Malaysia case, while Carson and al. (1997) have exposed that all pollution indicators decline with increasing income in the $50 \mathrm{U}$ States. 
Moreover, the case of water pollution is more mitigated or moderated. Many studies have had difficulty in proving a significant rapport between water pollution indicators and income per capita (Torras and Boyce, 1998; Paudel and al, 2005). However, the existence of an EKC for biological oxygen demand (BOD), the chemical oxygen demand (COD), arsenic and nitrates are verified throughout several studies (Sigman 2002; Cole 2004; Solakoglu 2007).

Yet, the most significantly studied indicator for the exploitation of natural resources is deforestation. Some studies have confirmed that the EKC hypothesis as applied to deforestation while other have invalidated it (Sahfik, 1994; Heerink and al 2001; Barbier 2001; Culas 2007, Rodriguez-Meza and al, 2003). A myriad of other environmental indicators were with the aim of demonstrating an EKC type relationship. With the exception of heavy metal and toxic intensity factors, these indicators are not generally consistent with the EKC hypothesis.

\section{Empirical model estimation and results interpretation}

Our task is to investigate the existence of a relationship in the form of an inverted $U$ between water pollution per worker and income per capita for $\mathrm{EU}^{1}$ and $\mathrm{SEMC}^{2}$. The first indicator is approximated by the BOD emission measured in kilograms per worker, is a chemical procedure for determining how fast biological organisms use up oxygen in water. BOD emission could be easily measured by standard procedures, which help guarantee consistency in data quality across countries (Sigman, 2002). Real GDP per capita is measured in constant 2000US dollars. All data came from World Development Indicators (WDI 2008).

To achieve our purpose, we are applying reduced form estimation function (Equation 1 below), which straightly relates water pollution per capita $\left(\mathrm{WP}_{\mathrm{it}}\right)$ to GDP per capita $\left(\mathrm{GDPC}_{\mathrm{it}}\right)$.

$$
\text { LBOD it }=\chi i+\beta t+\alpha 1 L G D P C i t+\alpha 2(L G D P C)^{2}+\alpha 3(L G D P C)^{3}+\alpha 4 \text { trend }+\varepsilon i t
$$

Where: Indices $i$ and t represent the countries and the years of period under review.

$\chi_{i}$ indicates the countries constant and non-measurable specific effects.

$\beta_{\mathrm{t}}$ designates the specific time effects, which enable to take into account the stochastic shocks common to all countries over different periods.

Using panel data, the first posed problem has been the variables stationarity. Among the recently developed stationarity tests, we can refer to the unit root test of Im, Pesaran, Shin (2003) for our model in table 1 below.

\footnotetext{
${ }^{1}$ EU: Austria, Belgium, Denmark, Finland, France, Germany, Greece, Ireland, Italy, Luxembourg, Netherlands, Portugal, Spain, Sweden and United Kingdom.

${ }^{2}$ SEMC: Algeria, Egypt Arab Republic, Israel, Jordan, Lebanon, Morocco, Syrian Arab Republic, Tunisia Turkey
} 
Table 1: Unit root tests of different variables

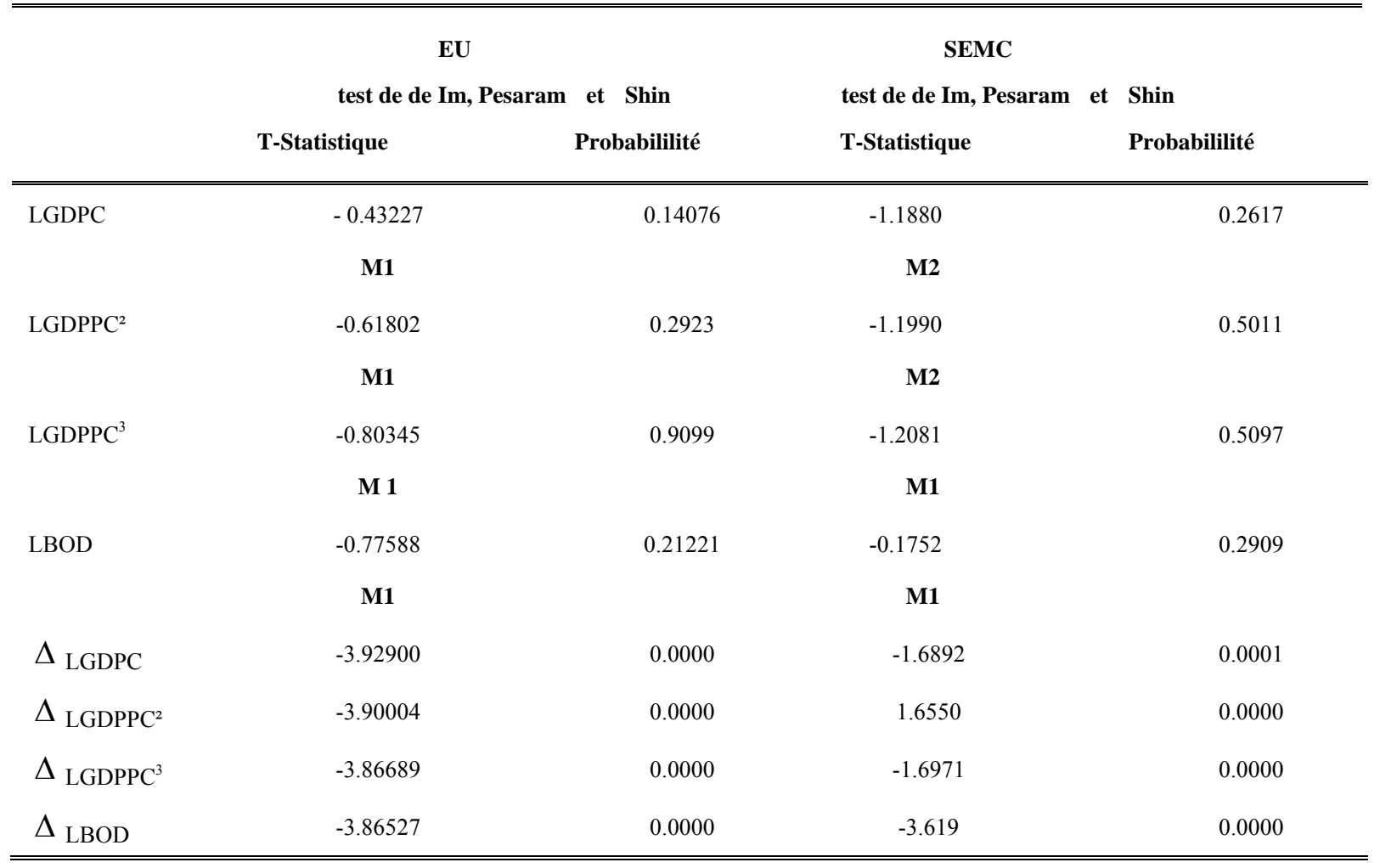

$\mathrm{M}_{1}$ : model 1 without constant and trend, $\mathrm{M}_{2}$ : model 2 with constant but without trend, $\mathrm{M}_{3}$ : model 3 with constant and trend.

Regarding the applied tests, we don't reject the unit root null hypothesis. After having differentiating the different series, the tests have indicated the stationarity for all variables with both methods at a significance level of $1 \%$. Assuming that the variables of this model are I (1), a cointegration test is then possible.

The cointegration concept could be defined as being a systematic long-term movement relationship between two or more economic variables. The tests of Granger (1981) and Johansen (1995) are only indicated as far as time series are concerned and do not deal with the panel data. To note, several tests have been developed within the framework of panels: the tests of no cointegration panel data proposed by Pedroni (2004), Kao and al (2000) who are testing equivalent or analogous residual to those tests proposed by Engle and Granger (1987) in the context of time series. Groen and Kleibergen (2003), have been in turn, inspired from the works of Johansen $(1991,1995)$ for the aim of proposing some tests based on likelihood ratio within a system whereas a priori the number of cointegration relationships is unknown. In addition, Pedroni (1997) proposed various tests for cointegration in two steps aiming at apprehending the null hypothesis of no single intra-individual cointegration for both homogeneous and heterogeneous panels. Pedroni (2004) proposes an extension in the case, where the cointegration relationships encompass more than two variables and, develops seven tests based on residues estimation of the long-term model. 
Pedroni's tests consider the heterogeneity through the means of parameters that can differ among individuals. Thus, under the alternative hypothesis, there exists a cointegrating relationship for each individual and the parameters of this as not necessarily the same for each individual in the panel (Hurlin and Mignon, 2007). The Pedroni application of cointegration test to the SEMC and the EU data depicts the following results in table 2 below.

Table 2: Test of Peter Pedroni (2004) for water pollution

\begin{tabular}{|c|c|c|c|c|c|c|c|}
\hline Model type & Rho-stat & $v$-stat & pp-stat & Adf-stat & Rho-stat & pp-stat & Adf-sta \\
\hline Quadratic Model SEMC & 1.55787 & 1.14619 & 1.485116 & 2.009262 & -3.682044 & -3.650454 & 3.978607 \\
\hline Cubic Model SEMC & 1.048722 & 0.12227 & 0.856497 & 0.202349 & -2.305374 & -1.908841 & -3.106248 \\
\hline Quadratic Model EU & -1.78771 & 1.52950 & -2.59094 & -3.32298 & 1.12593 & -2.50841 & -3.44055 \\
\hline Cubic Model EU & -1.71191 & 1.08034 & -2.36865 & -3.29760 & 0.16092 & -1.76320 & -3.21405 \\
\hline
\end{tabular}

From the results of Perdroni's cointegration tests, we note that all statistics are inferior to the critical value of the normal distribution law for at a threshold of $5 \%(-1.64)$. Thus, the whole set of these tests requires the existence of a cointegrating relationship. Hence, for accomplishing cointegration tests on panel data and in order to obtain an estimation of the cointegrating vectors, it is necessary to apply an effective method of estimation. In this context, we can distinguish several techniques; namely, the FMOLS method used by Pedroni, the DOLS method (dynamic least square) method, the GMM and ML methods (generalized method of moments and maximum likelihood).

Phillips and Moon (1999) illustrated that in the context of panel data techniques FMOL and DOLS techniques lead to asymptotically distributed estimators conforming to a normal centered reduced law. Still, Pedroni (1997) affirms that OLS estimators are super-convergent while their asymptotic distribution is biased skewed and depend on the nuisance parameters. According to Pedroni, these problems could be even better defined and pronounced in the presence of heterogeneity. As far as our model is concerned, the estimation of these cointegrating vectors via the FMOLS method and for the whole panel is summarized in the following table 3 . 
Table 3: Cointegration vector for water pollution

cointegration Equation for both samples SEMC and EU

Quadratic Model SEMC

$L B O D=9.14 L^{L} G P C^{*}-0.63 L G D P C^{2 *}$

(9.99) $\quad(-9.92)$

Cubic Model SEMC

$L B O D=-7.52 L G D P C+2.83 L G D P C^{2}-0.21 L G D P C^{3}$

$(-0.99) \quad(0.87) \quad(-0.75)$

Quadratic Model EU

$L B O D=25.74 L G D P C^{*}-1.31 L G D P C^{2 *}$

$(25.431) \quad(-25.46)$

Cubic Model EU

$L B O D=-221.86 L G D P C+23.90 L G D P C^{2}-.0 .86 L G D P C^{3}$

$(-0.32) \quad(0.52) \quad(-0.74)$

* Significant at threshold of $1 \%$

The table results prove that for the quadratic model, all coefficients of the long-term cointegration equation are statistically significant at a threshold of $1 \%$. However, those pertaining to the cubic model are non-significant, which eliminates the possibility of getting an $\mathrm{N}$ shaped or a reversed N-shaped EKC. Concerning the Quadratic model, we notice that there is a change in the sign of the coefficients from positive to negative, thus showing the existence of an inverted U-shaped EKC. (See Figures 1 and 2 below).

The turning points are at 1413.70US\$ [=exp 9.14/2*(-0.63)] and 18475US\$ [= exp $25.74 / 2 *(-1.31]$, respectively for the sample of SEMC and that of EU.

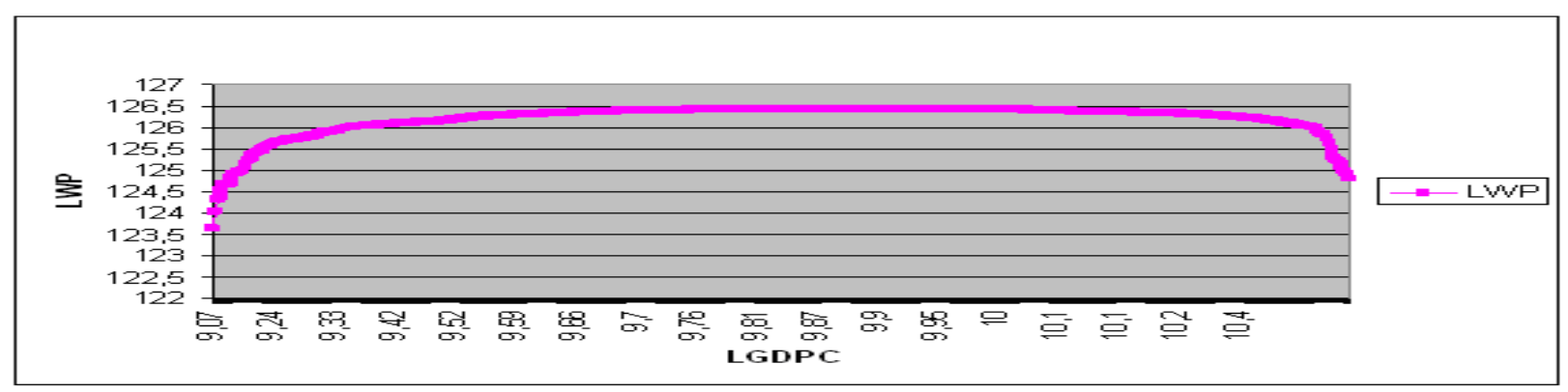

Figure 1. EKC specific to the European Union 


\section{Macrothink}

The EKC for the EU shows that the pollution-decoupling economic growth has generated a level of income per capita that is equal to 18475 US. This level is higher than those detected by Sigman, 2002 or Elliott, 2004 and less than Chien-Chiang Lee and al, 2009. There is evidence of an inverted U-shaped EKC relationship between real income and BOD emissions, implying that the initial stage of these countries' economic development encourages domestic factories to produce products, including both clean and dirty goods. The residents of these economies may demand higher levels of environmental quality and ask the government to impose more an environmental regulation policy, like pollution taxes on factories which produce dirty goods, and thus environmental quality can be improved. Although our empirical results indicate no evidence of an $\mathrm{N}$-shaped relationship between real income and BOD emissions, these countries should still keep up efficiency improvements with continuing growth of production to prevent environmental erosion.

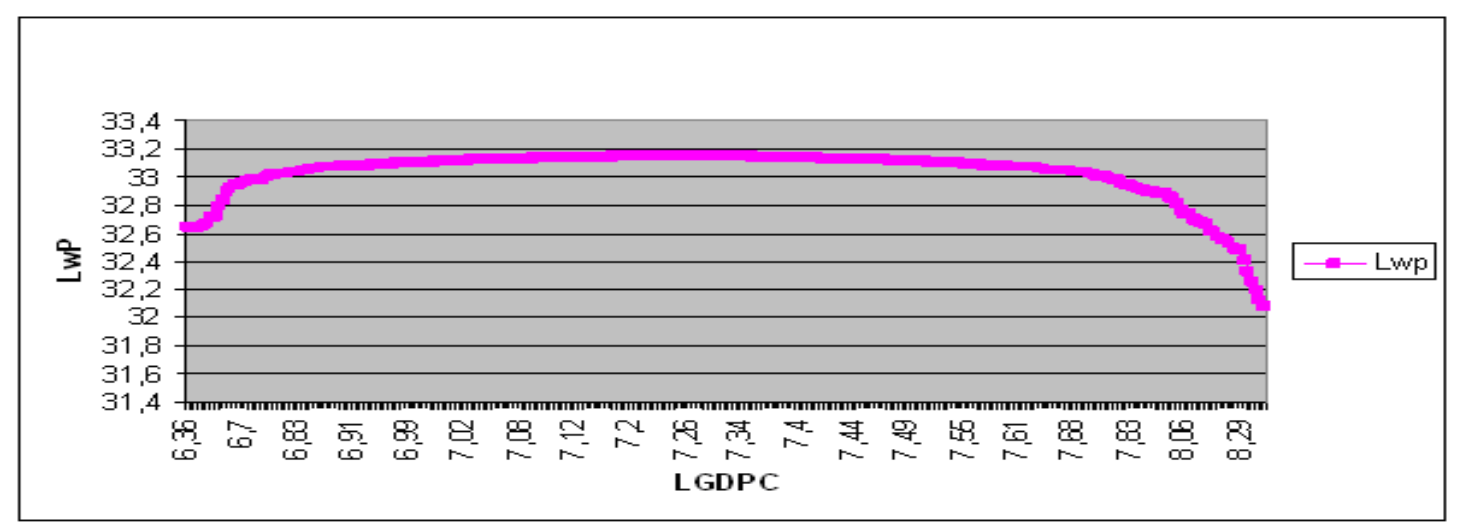

Figure 2. EKC specific to the SEMC

The SEMC related to EKC confirms that if the level of income per capita of a country belonging to this set group is inferior to than of $1413.70 \mathrm{U} . \mathrm{S} \$$, the water pollution in this country increases with income growth as it was for example, the case in Tunisia before 1984, Egypt before 1999 and Syria before 2006 (WDI 2007). Yet, after reaching or the threshold of 1 413.70 , this pollution is changing in the opposite direction to increase income and there will be pollution and decoupling economic growth. This result is similar to that of Solakoglu (2007) how examines the EKC hypothesis for EU-accessed and non-EU-accessed transition countries, respectively, and indicates that the estimated turning points of water pollutants are between, approximately, 1815US\$ and 5527 US\$.

Although these countries have a turning point fairly low, they should still establish some environmental regulation policy to maintain a low level of BOD emissions with continuing Growth of the economy.

To detect a CKE for the particular case of Tunisia, we use the same equation (1) for time series data. 
The table 4 shows that the number of lags of the variables in question is equal to 1 . Hence the use of the DF tests (Table 5).

Table 4: Determining the number of maximum delay for the model variables

\begin{tabular}{cc}
\hline \hline Variables & Numbers of maximum delay \\
\hline \hline LGDPC & 1 \\
LGDPC $^{2}$ & 1 \\
LGDPC $^{3}$ & 1 \\
LBOD & 1 \\
\hline \hline
\end{tabular}

Table 5: Dickey and Fuller test (1979-1981)

\begin{tabular}{lcccc}
\hline \hline Variables & LGDPC & LGDPC $^{2}$ & LGDPC $^{3}$ & LBOD \\
\hline \hline & -3.36601 & -2.411748 & 0.327520 & 3.741858 \\
level & M3** & M2 & M1 & M1 \\
& -3.533083 & -2.941145 & -1.94985 & -2.941145 \\
Critical value & & & & -3.095331 \\
First difference & -6.186672 & -5.193681 & -21.69259 & $\mathbf{M 1}$ \\
& $\mathbf{M 3}$ & $\mathbf{M 2}$ & $\mathbf{M 1}$ & -2.943427 \\
Critical value & -3.533083 & -2.943427 & -1.950117 & \\
\hline \hline
\end{tabular}

$\mathrm{M}_{1}$ : model 1 without constant and trend, $\mathrm{M}_{2}$ : model 2 with constant but without trend, $\mathrm{M}_{3}$ : model 3 with constant and trend.

The results of Table 5 show that all variables are non-stationary in levels, but stationary in first difference. Since the variables are 1(1) the next step is to test if they are cointegrated using the Johansen full information maximum likelihood.

Table 6: Johensen cointegration test results

\begin{tabular}{|c|c|c|c|c|c|c|}
\hline \multirow[b]{3}{*}{ Nulle hypothesis } & \multicolumn{3}{|c|}{$\lambda_{\text {trace }}$} & \multicolumn{3}{|c|}{$\lambda_{\max }$} \\
\hline & \multicolumn{6}{|c|}{$\mathrm{X}_{1 \mathrm{t}}=\left(\mathrm{LBOD}\right.$ LGDPC LGDPC $\left.{ }^{2}\right)$} \\
\hline & $\mathrm{r}=0$ & $\mathrm{r} \leq 1$ & $\mathrm{r} \leq 2$ & $\mathrm{r}=0$ & $\mathrm{r}=1$ & $\mathrm{r}=2$ \\
\hline Alternative hypothesis & $\mathrm{r} \geq 1$ & $\mathrm{r} \geq 2$ & $\mathrm{r} \geq 3$ & $\mathrm{r}=1$ & $\mathrm{r}=2$ & $\mathrm{r}=3$ \\
\hline Statistic test & 78.13 & 25.88 & 5.62 & 52.25 & 20.25 & 5.62 \\
\hline 0.05 critical value & 42.91 & 25.87 & 12.51 & 25.82 & 19.38 & 12.51 \\
\hline Cointegration vector & \multicolumn{6}{|c|}{$L B O D=-48.47+6.87 L G D P C-0.48 L G D P C^{2}$} \\
\hline
\end{tabular}

Tables 6 show that there is one cointegration vector between water pollution and the GDPC and that, for the quadratic model, all coefficients of the long-term cointegration equation are statistically significant at a threshold of $1 \%$. The turning point is, for the case of Tunisia, at 1282.09US\$ at constant price of 2000. 


\section{Conclusion}

In this work, we have examined the relationship between income per capita and environmental quality in two regions having different levels of development in order to detect the existence of an EKC. In the first stage, we have conducted a literature review of theoretical and empirical analysis on EKC. Although, it seems relatively easy to find a relationship in the form of inverted $U$ trough micro-economic formalizing and transversal estimates, the great sensitivity of the estimated shape of EKC with the sample, the time period, the estimation method and the function form selected have only increased our doubt about the existence of a EKC "standard" for all countries.

In a second step, we have estimated the relationship between water pollution and GDP per capita by applying the cointegration technique. The model results have confirmed that the water pollution and GDP per capita variables are cointegrated which implies the existence of a single long-term relationship. Estimating this long-term relationship implies the existence of inverted U-Shaped EKC specific to each subject of our study. These curves predict a turning point between income per capita and industrial WP emissions around 1413.70 US\$ and 18475 US\$ at constant prices of the year 2000 respectively for the sample consisting of SEMC and that of the EU. This difference can be justified by a twofold divergence between these two regions in terms of income and level of economic structure. Hence, the importance of a structural EKC study relative to these two sets of countries. We might well wonder, such an analysis, could unveil the enigma of the environmental Kuznets curve for the EU and especially for the SEMC.

\section{References}

Abdul Jalil and SyedF.Mahmudb. (2009). Environment Kuznets curve for CO2 emissions: A cointegration analysis for China. Journal of Energy Policy. VOL 37(12) PP 5167-5172.

Azomahou, T., F. Laisney and N. Van Phu. (2006). Economic development and CO2 emissions: A non parametric panel approach, Journal of Public Economics 90, 1347-1363.

Barbier, Edward B. (2001). The economics of tropical deforestation and land use: an introduction to the special issue. Land Economics 77 (2), 155-171.

Carson R.T., Jeon, Y., Mc Cubbin, D.R. (1997). The relationship between air pollution emissions and income: US data. Environment and Development Economics N 2, pp. 433-450.

Cavlovic, T. A., K. H. Baker, R. P. Berrens, and K.Gawande. (2000). "A Meta-analysis of Environmental Kuznets Curve Studies" Agricultural and Resource Economics Review 29, $32-42$.

Chien-Chiang Lee, Yi-BinChiu \& Chia-HungSun. (2009). The environmental Kuznets curve hypothesis for water pollution: Do regions matter? Energy policy, vol 5, 113-126.

Cole, M.A., A.J. Rayner et J.M. Bates. (1997). The environmental Kuznets curve: an empirical analysis. Environment and Development Economics, 2: 401-416. 


\section{Macrothink}

Environmental Management and Sustainable Development

ISSN 2164-7682 2012, Vol. 1, No. 1

Cole. M.A. and R. J. R. Elliott. (2003). Determining the trade-environment composition effect: the role of capital, labor and environmental regulations. Journal of Environmental Economics and Management, 46(3): 363-383.

Cole, M.A. (2004). Trade, the pollution haven hypothesis and the environmental Kuznets curve: examining the linkages. Ecological Economics, 48(1): 71-81.

Culas, R.J. (2007). Deforestation and the environmental Kuznets curve: an institutional perspective. Ecological Economics 61 (2), 429-437.

Dasgupta, S., Laplante, B., Wang, H., Wheeler, D. (2002). Confronting the environmental Kuznets curve. The Journal of Economic Perspectives 16 (1), 147-168.

Dinda, S, (2004). Environmental Kuznets curve hypothesis: a survey. Ecological Economics 49 (4), 431-455.

De Bruyn, S.M., van den Bergh, J.C.J.M., Opschoor, J.B., (1998). Economic growth and emissions: reconsidering empirical basis of environmental Kuznets curves. Ecological Economics 25 (2), 161-175.

Elif Akbostanc1, Serap Turut As1k, G. Ipek Tunc. (2009). The relationship between income and environment in Turkey: Is there an environmental Kuznets curve? vol. 37, no3, pp. 861-867.

El-Fadel, M., Massoud, M. (2000). Particulate matter in urban areas: health-based economic assessment. The Science of the Total Environment, 257 (2-3), 133-146.

Engle, R., Granger, C.W.J. (1987). Cointegration and error correction: representation, estimation and testing. Econometrica 55, 251-276.

G. İpek Tunç, Serap Türüt-Aşık, Elif Akbostanc1. (2009). The relationship between income and environment in Turkey: Is there an environmental Kuznets curve? Journal of Energy Policy Volume 37, Issue 11, Pages 4177-4996.

Grossman, G.M., Kruger, A.B. (1991). Environmental impacts of the North American free trade agreement. NBER Working Paper 3914.

Grossman, G.M, -Kruger, A.B. (1995). Economic growth and the environment. Quarterly Journal of Economics 110 (2), 353-377.

Groen, Jan J J and Kleibergen, Frank. (2003). Likelihood-Based Cointegration Analysis in Panels of Vector Error-Correction Models, Journal of Business \& Economic Statistics, American Statistical Association, vol. 21(2), pages 295-318, April.

Harbaugh, W.T., Levinson, A., Wilson, D.W. (2002). Re-examining the empirical evidence for an environmental Kuznets curve. The Review of Economics and Statistics 84 (3), 541-551.

Heerink, N., Mulatu, A., Bulte, E. (2001). Income inequality and the environment: aggregation bias in environmental Kuznets curves. Ecological Economics 38 (3), 359-367.

Halicioglu, F. (2009). An econometric study of CO2 emissions, energy consumption, income and foreign trade in Turkey. Energy Policy 37 (3), 1156-1164. 
Hurlin C and Mignon, V. (2007). "Une Synthèse des Tests de Cointégration sur Données de Panel", Economie et Prévision.

Im, K.S., Pesaran, M.H., Shin, Y. (2003). Testing for unit roots in heterogeneous panels. Journal of Econometrics 115 (1), 53-74.

Johansen, S., (1995). Likelihood-Based Inference in Cointegrated Vector Autoregres- sive Models. Oxford University Press, Oxford. ISBN 0-19-877449-4.

Kao, C, Chiang, M-H. (2000). On the estimation and inference of a cointegrated regression in panel data. In: Baltagi, B.H. (Ed.), Non stationary Panels, Panel Cointegration and Dynamic Panels, In: Advances in Econometrics, vol. 15. JAI Press, Amsterdam.

Levin, A, Lin, C. F, \& Chu, C. (2002). Unit root tests in panel data: asymptotic and finite-sample properties. Journal of Econometrics 108 (1), 1-24.

Moomaw,W.R.,Unruh,G.C. (1997). Are environmental Kuznets curve misleading us? The case of CO2 emissions. Environment and Development Economics 2, 451-463.

Magnani, E. (2000). The environmental Kuznets Curve, environmental protection policy and income distribution. Ecological Economics 32: 431-443.

Paudel, Krishna P., Zapata, Hector, Susanto, Dwi. (2005). An empirical test of Environmental Kuznets Curve for water pollution. Environmental and Resource Economics 31 (3), 325-348.

Panayotou, T. (1993). Empirical Tests and Policy Analysis of Environmental Degradation at Different Stages of Economic Development. Working Paper $\mathrm{n}^{\circ} 238$ Technology and Employment Programme, Geneva: International Labor Office.

Panayotou, T. (1997). Demystifying the environmental Kuznets curve: turning a black box into a policy tool. Environment and Development Economics 2 (4), 465-484.

Perman, R., Stern, D.I. (2003). Evidence from panel unit root and cointegration tests that the environmental Kuznets curve does not exist. The Australian Journal of Agricultural and Resource Economics 47 (3), 325-347.

Pedroni Peter. (1997). Panel Cointegration: Asymptotic and Finite Sample Properties of Pooled Time Series Tests with an Application to the PPP Hypothesis: New Results, Indiana University, San Diego (1997).

Pedroni, P. (2004). Panel cointegration: asymptotic and finite sample properties of pooled time series tests with an application to PPP hypothesis: new results. Econometric Theory 20 (3), 597-627.

Peter C.B. Phillips \& Hyungsik R. Moon. (1999). Linear Regression Limit Theory for Non stationary Panel Data, Cowles Foundation Discussion Papers $N^{\circ} 1222$, Cowles Foundation, Yale University.

Quah and Boon. (2003). The economic cost of particulate air pollution on health in Singapore Journal of Asian Economics, 14 (2003) 73-90. 


\section{Macrothink}

Environmental Management and Sustainable Development

ISSN 2164-7682 2012, Vol. 1, No. 1

Rodriguez-Meza, Jorge, Southgate,Douglas, Gonzalez-Vega, Claudio. (2003). Rural poverty, household response to shocks, and agricultural landuse: panel results for El Salvador. Department of Agriculture, Environmental and Developmental Economics, Ohio State University. Sept. 2003.

Sigman, H. (2002). International spillovers and water quality in rivers: do countries free ride? American Economic Review 92, 1152-1159.

Solakoglu, E. G. (2007). The effect of property rights on the relationship between economic growth and pollution for transition economies. Eastern European Economics 45, 77-94.

Stern, D.I., Common, M.S. (2001). Is there an environmental Kuznets curve for sulfur? Journal of Environmental Economics and Management 41 (2), 162- 178.

Shafik N. (1994). Economic Development and Environmental Quality: An econometric Analysis. Oxford Economic Papers 46: 757-773.

Shafik N. and Bandyopadhyay. (1992). Economic Growth and Environmental Quality: Time Series and Cross- Country Evidence, World Bank Policy Research Working, Paper, WPS 904, ashington DC: Banque Mondiale.

Selden Thomas M. \& Song Daqing. (1994). Environmental Quality and Development: Is There a Kuznets Curve for Air Pollution Emissions?. Journal of Environmental Economics and Management, Vol 2: pp 147-162.

Stern, D.I. (2004). The rise and the fall of environmental Kuznets curve. World Development $32(8), 1419-1439$.

Torras, M., and J.K. Boyce. (1998). Income, Inequality, and Pollution: A Reassessment of the Environmental Kuznets Curve, Ecological Economics 25(2):147-160.

Vincent, J.R. (1997). Resource depletion and economic sustainability in Malaysia. Environment and Development Economics 2(1):19-37.

\section{Copyright Disclaimer}

Copyright reserved by the author(s).

This article is an open-access article distributed under the terms and conditions of the Creative Commons Attribution license (http://creativecommons.org/licenses/by/3.0/). 